\title{
La mirada cosmologicista sobre el género de las mujeres indígenas en la antropología del Chaco argentino: una crítica
}

The gender cosmologic approach of indigenous women in the anthropology of the Argentine Chaco: a review

\section{Mariana D. Gómez.}

\section{(2) OpenEdition}

\section{Journals}

\section{Electronic version}

URL: http://journals.openedition.org/corpusarchivos/1765

DOI: 10.4000/corpusarchivos. 1765

ISSN: 1853-8037

\section{Publisher}

Diego Escolar

\section{Electronic reference}

Mariana D. Gómez., « La mirada cosmologicista sobre el género de las mujeres indígenas en la antropología del Chaco argentino: una crítica », Corpus [En línea], Vol. 7, No 1 | 2017, Publicado el 26 junio 2017, consultado el 19 abril 2019. URL : http://journals.openedition.org/corpusarchivos/1765 ; DOI : 10.4000/corpusarchivos. 1765

This text was automatically generated on 19 April 2019.

Licencia Creative Commons: Atribución-NoComercial 2.5 Argentina (CC BY-NC 2.5 AR) 


\title{
La mirada cosmologicista sobre el género de las mujeres indígenas en la antropología del Chaco argentino: una crítica
}

\author{
The gender cosmologic approach of indigenous women in the anthropology of \\ the Argentine Chaco: a review
}

Mariana D. Gómez.

\section{Introducción}

1 En este artículo me propongo realizar una crítica a lo que denomino mirada cosmologicista sobre el género de las mujeres indígenas que impera en la antropología del Chaco contemporánea, enmarcada en una perspectiva ontologicista y cosmologicista más amplia sobre los pueblos indígenas. La mirada cosmologicista sobre el género en la antropología del Chaco parte de una conceptualización del género (como fenómeno y como categoría de análisis) que prioriza los aspectos simbólicos o la reconstrucción de la estructura simbólica ligada a las cosmologías indígenas. Esto se realiza a través del análisis de pares contrarios antagónicos que expresan asociaciones simbólicas para cada género (mujer: naturaleza / hombre: cultura), siendo los materiales de análisis privilegiados para ello algunos mitos (principalmente el mito sobre el origen de las mujeres) y un antiguo ritual de iniciación femenina que compartían los grupos wichís, qom y pilagá.

2 A continuación, en primer lugar, realizaré una genealogía con el objetivo de mostrar las influencias de tres antropologías que acabaron por cristalizarse en la mirada cosmologicista sobre el género. En segundo lugar, me detendré en mostrar cómo se viene aplicando dicha mirada en algunos estudios etnográficos sobre mujeres qom y wichís. Estos dos grupos, a pesar de pertenecer a grupos lingüísticos distintos (los primeros 
pertenecen a la familia lingüística mbayá-guaycurú, mientras que los wichí a la matacomataguayo), comparten el mito de origen de las mujeres y el antiguo ritual de iniciación y son los más numerosos en el actual Chaco argentino, por eso me focalizo solo en ellos, además de que conozco con más detalle el corpus bibliográfico. Aquí me detendré en señalar dos aspectos problemáticos: su ahistoricidad y esencialismo, por un lado, y la omisión sobre la desigualdad de género, por el otro, características que, como desarrollamos en otro lugar (Gómez y Sciortino 2015), podrían tener usos ideológicos por fuera de los debates académicos e implicancias concretas en la vida de las mujeres indígenas. Finalmente, y en cuarto lugar, me detendré en caracterizar una propuesta alternativa a la perspectiva cosmologicista que, sin desestimar la presencia de esquemas de visión y di-visión míticos que todavía persisten en el imaginario social de género de las personas que viven en las comunidades tobas donde realicé mi trabajo de campo (tobas del oeste, tobas-pilagá o ñachilamoléec [gente del río abajo del Pilcomayo]), parte de una perspectiva histórica sobre la construcción cultural del género. Esta aproximación crítica al tratamiento del género de las mujeres indígenas no pretende ser exhaustiva, la única posible ni recuperar todo lo dicho al respecto. Se trata tan solo de una evaluación crítica de la mirada cosmologicista, tomando como ejemplo algunos estudios realizados en grupos wichís y qom de los últimos años.

\section{Antecedentes cristalizados en la mirada cosmologicista sobre el género: una genealogía posible}

3 Aquí sostengo la hipótesis de que en la actual mirada cosmologicista sobre el género en la antropología del Chaco se cristalizan las influencias de tres antropologías: 1) la antropología pionera realizada por etnógrafos europeos durante las primeras décadas del siglo XX y cuyas publicaciones todavía muestran utilidad, dadas las descripciones sobre la vida indígena pre procesos de misionalización que contienen; 2) la etnología de Bórmida: un legado todavía presente en los imaginarios antropológicos sobre los indígenas del Chaco (Gordillo 2006b, p.3) la etnología amazónica (puesto que la región del Gran Chaco comparte con la Amazonia su pertenencia a las Tierras Bajas), donde prevalecieron corrientes teóricas como el estructuralismo francés, el funcional-estructuralismo inglés a lo que hay que sumarle el reciente desembarco del perspectivismo -entendido como una filosofía indígena o paradigma centrado en el análisis de los vínculos entre humanos y nohumanos en las ontologías amerindias (Viveiros de Castro 2004, 2010) - y los debates en torno a la división naturaleza/cultura en la antropología francesa (Descola 2001). A continuación señalo los trabajos de autores que, en el marco de alguna de estas tres antropologías, que convergieron en la mirada cosmologicista actual, se propusieron analizar aspectos del género femenino de manera central o tangencial.

4 Los primeros abocados a describir los rituales de iniciación de las mujeres, los tabúes seguidos durante estados fisiológicos (menstruación, embarazo, amamantamiento) y sociológicos (pubertad, adultez, ancianidad, viudez), así como el acercamiento a aspectos del mundo femenino (tatuajes, cantos, danzas, producción de artesanías), fueron etnógrafos europeos que recorrieron distintas zonas del Chaco argentino, boliviano y paraguayo tales como Mètraux (1931, 1948), Karsten (1932) y Nordenskiöld (1912), por mencionar solo a algunos. Ellos dejaron un conjunto de descripciones, especialmente 
sobre los rituales de iniciación dado que estos mantuvieron visibilidad en las aldeas y tolderías hasta las primeras décadas del siglo XX o hasta que los grupos indígenas comenzaron a agruparse alrededor de las misiones. Las descripciones del antiguo ritual de iniciación femenina, la recopilación y transcripción de mitos, descripciones sobre la división sexual del trabajo, los roles asignados a cada "sexo" y la afirmación de que las mujeres indígenas ejercían una alta libertad sexual y autonomía en la elección del cónyuge fueron algunas de las ideas que decantaron en estudios posteriores (Braunstein 1974; Idoyaga Molina 1976; Kidd 1995; Palmer 2005). Estas primeras etnografías continúan siendo utilizadas como fuentes de información etnográfica a las cuales recurrir para discutir, elaborar y sostener nuevos argumentos en las etnografías actuales.

5 Después de los trabajos de Nordenskiöld, Karsten, Métraux y otros etnógrafos locales (argentinos) como Enrique Palavecino, los pueblos indígenas del Chaco reaparecieron en la década de 1970 y principios de la siguiente en el marco de la etnología fenomenológica liderada por Marcelo Bórmida: una corriente dominante en la antropología porteña cuyos postulados se anclaron en una curiosa síntesis de la fenomenología europea (Gordillo 2006, 2006b, 2006c) ${ }^{1}$, también connotada como del establishment (Guber 2009, p. 16). A diferencia de los debates que por esos mismos años se desarrollaban en otras academias latinoamericanas y en el amplio movimiento indígena que se configuraba en el continente, durante la década de 1970 y hasta mediados de la siguiente, los indígenas del Chaco argentino fueron retratados como guardianes expectantes de los restos de sus culturas, narradores de sus costumbres, mitos y concepciones nativas, prescripciones casi mecánicas para la "conciencia mítica" a la que se entregó esta corriente, anacrónica desde su nacimiento. Gordillo afirma que:

...la fenomenología bormidiana reformuló este viejo imaginario sobre el Chaco, escribiendo 'mítico' donde antes decía 'salvaje' y reemplazando la imagen del guerrero indómito por la del 'hombre etnográfico'. Pero esta reformulación siguió estando basada en imágenes naturalizadas de diferencia, ancladas en última instancia en el legado de la conquista militar de esta región. Siendo una de las principales fuentes de material etnográfico sobre el Gran Chaco, esta escuela contribuyó a reproducir la imagen de que los indígenas son personas de la que nos separaría, como diría Bórmida (1969b, p. 62), 'un abismo cultural' (2006b, p. 275). ${ }^{2}$

En el marco de la etnología de Bórmida varios trabajos abordaron aspectos de la vida de las mujeres ayoreo, qom, pilagá y wichí, particularmente aquellos vinculados a las representaciones de lo femenino en las narrativas míticas y las concepciones sobre los procesos de concepción, gestación y reproducción o, en otros términos, aspectos fisiológicos femeninos considerados desde la perspectiva nativa. Entre sus exponentes más importantes se encuentran Idoyaga Molina y sus trabajos sobre concepciones nativas del embarazo, la reproducción y la sexualidad entre grupos pilagá, wichí y qom (1976, 1976/77, 1986/87), aportando algunas ideas interesantes como la de sexualidad conyugal y no-conyugal para referirse a las prácticas sexuales y a sus estados emocionales en los grupos pilagá de Formosa con los que trabajó. En una publicación más reciente (1999) la autora sintetizó los datos recogidos durante tres décadas sobre estas cuestiones. Otros exponentes de la etnología de Bórmida fueron Celia Mashnshnek con sus trabajos sobre las nociones ayoreo del Chaco Boreal acerca de la menarca, la concepción y el alumbramiento (1986), y artículos de De los Ríos sobre narrativas del ciclo vital en miembros de grupos wichís (1976/80).

7 Estos autores, al encuadrarse dentro de la etnología bormideana, se concentraron en transcribir los relatos de sus informantes sobre sus creencias, concepciones y mitos, y 
tomaban a estas narrativas como manifestaciones de una "conciencia mítica" (arcaica). Los significados, las intenciones y las acciones se explicaban remitiéndose a los roles que jugaban animales, personas y otros seres no-humanos (denominados por esta corriente teofanías) en configuraciones cosmológicas-míticas del mundo. Teniendo en cuenta la extensa crítica realizada a esta escuela (a sus supuestos teórico-epistemológicos y su práctica etnográfica) por Gordillo (2006b), tal vez solo nos resta recordar la crítica principal: el lugar central, primario y esencial que le otorgaban a las cosmologías nativas en la conciencia social de sus informantes, asumiendo que las cosmologías indígenas eran conjuntos de principios culturales que no se alteraban con el paso del tiempo (Idoyaga Molina 1999, p. 16). Una frase de Idoyaga Molina bien podría sintetizar lo anterior: "si bien la situación de contacto es de larga data y ha originado cambios y adaptaciones, puede decirse que las cosmovisiones nativas mantienen vigencia y que es a partir de las mismas que se entienden las alteraciones producidas" (1999, p. 163). ${ }^{3}$

argo, como ha señalado Gordillo (2006b), aquí reside una compresión de la cultura que hace "abstracción de las condiciones sociales e históricas que subyacen a la producción de significados" (p. 255), hay una explícita negación a mostrar el componente ideológico que toda cultura tiene (p. 260) o, dicho de otra forma, una negación a mostrar cuáles eran/son las condiciones de interlocución de sus informantes y los intereses ideológicos - sean estos conscientes o no- que cualquier persona asume a la hora de narrarle algo a otra; también Gordillo señaló que otro problema era la representación de los indígenas del Chaco como sujetos sumergidos y dominados por una conciencia irracionalista (conciencia mítica) que creaba "una perspectiva del mundo opuesta a los principios de la conciencia occidental" (p. 258); también se refiere a la ilusión de los bormidianos acerca de la posibilidad de hacer etnografía despojándose de sus presupuestos teóricos y de sus categorías de análisis ya que el objetivo rector era "comprender la cultura solo de la forma en que la experimentaban sus miembros" (p. 258) y, por último, apunta la falta de consideración de una "fenomenología anclada en la praxis humana" (Gordillo menciona que ni Bórmida ni sus discípulos alcanzaron a integrar los aportes de Merleau Ponty en su corpus teórico).

9 En síntesis, los discípulos de Bórmida - de quienes podemos rescatar el corpus de interpretaciones nativas que dejaron sobre distintos aspectos de la "construcción cultural del género femenino" (no utilizaban este último término) - partían de una concepción idealista de la cultura al situarse en la tradición de la Vertehen (comprensión) y "al hacer un uso parcial de la tradición fenomenológica” (Gordillo 2006b, pp. 256-258). Probablemente este y otros posicionamientos los hayan conducido a no reflexionar sobre las transformaciones en la conciencia social de sus informantes, a focalizarse solo en los aspectos irracionales de la conciencia dejando de lado los aspectos racionales, o a homologar la representación y la interpretación con la acción social. Tampoco se preguntaron si sus informantes, al mismo tiempo que podían relatarles sus concepciones supuestamente originales sobre el embarazo o la gestación, también podían cuestionarlas (algo que, todas/os los que hicimos investigación en comunidades del Chaco argentino sabemos que sucede en las instancias de conversación con nuestros interlocutores), ponerlas en suspenso o compararlas con aquellas concepciones basadas en los saberes de la biomedicina con las que se encontraron en las misiones religiosas; o en los escasos programas de asistencia estatal de los que eran objeto por aquel entonces (décadas del 70 y 80). De este modo, recolectaron concepciones nativas -en el marco de la realización de entrevistas- sin dar cuenta de los procesos de hibridez, imposición e intercambio 
cultural entre concepciones, prácticas y lógicas provenientes del mundo indígena y de diversos sectores de la sociedad hegemónica con los que se fueron encontrando. Si nos posicionáramos en el marco teórico idealista bormidiano diríamos que el concepto de cultura era asimilado en el concepto de cosmología -organización de los componentes del mundo mediante principios de visión y división- no contaminada por otros principios de visión y di-visión no indígenas. La interrelación entre los diferentes componentes de esta cosmología indígena podía verse en acción en la mitología, el ámbito de investigación privilegiado de la escuela de Bórmida (Gordillo 2006b, p. 260).

Un punto de inflexión con respecto de la etnología de Bórmida (o dentro de ella) es el artículo que publicó Braunstein en 1983 ya que es un trabajo de corte sociológico: un modelo para clasificar los rasgos de la estructura social de los grupos indígenas del Gran Chaco y sus sistemas de parentesco. Este artículo influyó en los antropólogos posteriores de la región puesto que comenzaron a establecer relaciones entre el ámbito cosmológico y aspectos de la estructura social, reconsideraron los roles masculinos y femeninos en el liderazgo, en las alianzas y en la regla de residencia matrilocal (una característica de la estructura social que comparten varios pueblos indígenas chaqueños). Así, a partir de 1990 aparecieron los trabajos de Guadalupe Barúa $(1994,1998,2007)$ sobre el parentesco y las normas matrimoniales entre los wichí del Chaco central; los de Cristina Dasso (2006) y el de Marcela Mendoza (2002) sobre liderazgo qom. Más recientemente situamos a la etnografía de John Palmer (2005) sobre los wichís (la cual contiene un capítulo donde analiza el lugar clave de las mujeres en la cosmología wichí y en las alianzas matrimoniales) y los estudios de Florencia Tola sobre parentesco en distintas parcialidades qom (2006).

11 La tercera influencia en la mirada cosmologicista actual se vincula a la apropiación en la antropología del Chaco contemporánea de los debates sobre la construcción de la persona, el parentesco y el género elaborados desde fines de la década de 1970 en adelante por autores de las academias brasileñas, francesa e inglesa para etnografiar grupos indígenas de Amazonía (Seeger, Da Matta y Viveiros de Castro 1979). Investigadoras del Chaco retomaron tópicos sobre el rol femenino entre los wichís (Barúa y Dasso 1999), las transformaciones históricas en las representaciones qom de la gestación y la concepción (Tola 1999, 2001), la construcción del cuerpo y la persona y diversos aspectos de la cosmología y la ontología de grupos qom (Tola 2012; Tola, Medrano y Cardin 2013; Wright 2008).

12 En síntesis, en la actual mirada cosmologicista sobre el género abrevan los aportes de estas tres antropologías. La etnología bormidiana aportó la idea de que existen principios cosmológicos nativos que determinan la organización de la conciencia (mítica) y de las experiencias nativas, incluyendo las que se vinculan con la construcción cultural del género. La etnología centrada en las características de la organización social inaugurada con las investigaciones de Braunstein (1983) llevaron a que la siguiente generación de antropólogos integrara a la perspectiva mítica-cosmológica los estudios sobre parentesco, liderazgo y estructura social. Finalmente la influencia de la etnología amazónica -en donde cosmología y estructura social ya se presentan de manera articulada en varias etnografías desde la década del 60 en adelante (ver Gregor y Tuzin 2001)-, puede verse en la apropiación local de los debates sobre el giro ontológico en la antropología del Chaco actual (Tola 2016), sumando los intereses por el estudio sobre la construcción de la persona y como parte de esta, de la construcción del género desde las teorías y epistemologías nativas (Tola 2012). Una idea común que comparten estas tres influencias 
es que los indígenas, a pesar de la transformación de sus condiciones materiales de existencia, continúan subjetivados de manera primordial hacia los principios míticos, cosmológicos y ontológicos de sus grupos de pertenencia.

\section{Caracterización de la mirada cosmologicista actual}

13 Si nos detenemos a analizar varios trabajos de los últimos años que tocan aspectos del género femenino en grupos wichís (Palmer 2005; Montani 2008; Barúa et. al 2008) y qom (Tola 1999, 2001, 2008; Gómez C. 2010; Gómez 2008; Citro 2008; Córdoba 2008), veremos que existe una tendencia a privilegiar un nivel de análisis estructuralista para comprender la posición social de las mujeres, observando su lugar en la estructura simbólica de los mitos y en el viejo ritual de iniciación, aspectos que permitirían mapear la estructura simbólica de género en el marco de cosmologías indígenas mayores.

Mi argumento es que este tipo de enfoque suele derivar en una comprensión estática sobre el género pues este parece hipostasiarse en una estructura simbólica (que además es construida como resultado del análisis antropológico), inalterable al paso del tiempo y desvinculada de las condiciones actuales de existencia y de los cambios históricos por los que atravesaron las/los qom y wichís. Así, el privilegio otorgado a la estructura simbólica de género en estos estudios suele estar acompañado de una visión que le otorga prioridad a las cosmologías nativas, asumiéndose que, a pesar de los procesos de semiproletarización y conversión socio-religiosa al cristianismo de las/los wichís y qom, los principios cosmológicos $u$ ontológicos propiamente indígenas son los determinantes a la hora de organizar la conciencia y la experiencia. Esto dificulta comprender y explicar la transformación de la estructura simbólica de género (las asociaciones simbólicas y sus lógicas de ordenamiento) en función de los cambios económicos, culturales y religiosos que atravesaron los pueblos indígenas del Chaco, por un lado, y la relación imaginaria (ambivalente y contradictoria) que los miembros de cualquier grupo social mantienen con ese orden simbólico complejo y dinámico, por el otro. Otra cuestión significativa pero de la que poco se habla es que el ritual que se les practicaba a las púberes en estado de menarca, tal como fue descripto por los antropólogos pioneros del Chaco en las primeras décadas del siglo XX, se ha transformado notoriamente: ya sea porque se ha replegado a la trastienda de los hogares, porque en varias comunidades se dejó de realizar al cuestionar su eficacia ritual o porque solo persisten algunas asociaciones simbólicas y acciones (vinculadas a tabúes) ligadas a la sangre menstrual. Por otra parte, en general, pocas personas - por lo general los miembros mayores o ancianos de las comunidadessuelen narrar los antiguos mitos, en los cuales, además, se han incorporado símbolos y esquemas de visión y división de origen cristiano.

Considerando este argumento como otro punto de partida, a continuación criticaré dos rasgos de la mirada cosmologicista actual presentes en los estudios señalados: 1) la producción de una condición de género estática y eterna, y 2) la omisión sobre las desigualdades de género.

\subsection{Una condición de género estática y eterna anclada en la estructura simbólica}

Comencemos por los trabajos sobre mujeres wichís. En la etnografía de Palmer, el viejo ritual de iniciación y el mito sobre el origen de las mujeres son los puntos de anclaje para 
comenzar el análisis sobre la condición de género de las mujeres. En el capítulo dedicado a la cosmología wichí, Palmer comienza por describir el ritual de iniciación femenina mediante el cual, antiguamente (aunque llamativamente el relato etnográfico del autor está situado en el presente), las jóvenes se convertían en mujeres desposables. El mito del origen de las mujeres busca establecer el rol conyugal de las mujeres (2005, p. 88):

Tanto el microcosmos como el macrocosmos son estructuras femeninas, de manera que el principio de feminidad constituye el marco en que se encuadra la cosmología wichí. Cabe aclarar que se trata específicamente del aspecto maternal de la feminidad. Para los wichí, la condición de mujer se define en términos de la maternidad. (...) Antes que nada las mujeres son madres, y la maternidad consiste antes que nada en la reproducción de los hombres (Palmer 2005, p. 86).

18 La domesticación de la sexualidad femenina y el matrimonio son dos caras de la misma moneda, que apunta en ambos casos a la defensa de los derechos masculinos. En otras palabras, el mito enseña que el matrimonio es el medio por el cual los hombres superan el estado primitivo del matriarcado, el cual los priva de sus derechos jurídicos como esposos y como padres (p. 90).

La posición nodal que las mujeres ocupan en la sociedad wichí les confiere una importancia cultural especial porque estimulan y procesan el producto masculino. Los hombres suministran las materias primas - carne cruda y semen- que las mujeres transforman en productos culturales en forma de carne cocida y seres humanos. Como tales, las mujeres wichí desmienten el paradigma estructuralista, según el cual 'la mujer es [...] naturaleza' (Lévi Strauss 1964, p. 275). Existe una complementariedad de género tal que los hombres y las mujeres wichí son iguales en cuanto a sus atributos naturales y culturales. El aspecto natural de la mujer radica, para los wichí, en el hecho de que es susceptible de desocialización (cf. Cordeu y De los Ríos 1982, p. 159; Palmer 2005, p. 94).

En suma, los hombres wichí 'forman a las mujeres' para que aquellas desempeñen un determinado papel cultural, tanto en lo político como en lo económico. Hoy en día los Wichí comentan que sus mujeres han degenerado por causa de la influencia corrosiva de la cultura no indígena. En particular, citan el abandono del rito de iniciación femenina desconocida para la sociedad dominante- para indicar que el modelo ideal de la mujer wichí ya no se forma. Un misionero católico de fines del siglo XIX afirmó con respecto a los Wehnayek Wichí que "si no fuera por sus mujeres, esta tribu habría desaparecido desde hace siglos" (Giannecchini [1898], p. 388). Siendo tan importante la función femenina, es previsible que la pérdida de identidad de la mujer wichí provocaría la desaparición de todo el pueblo (Palmer 2005, p. 95 subrayado mío).

21 Aquí, como podemos observar claramente, la condición de género de las mujeres wichí se proyecta hacia el orden simbólico de género que se construye en base al análisis de algunos mitos y del antiguo ritual de iniciación. Por un lado, habría un principio de feminidad que sería el marco en el que se encuadra toda la cosmología wichí y por esto debemos entender la asociación entre las mujeres wichís y la maternidad (que consistiría en la reproducción de los hombres). Existiría una complementariedad de género entre hombres y mujeres pues ambos serían iguales en sus atributos naturales y culturales $\mathrm{y}$, por ello, nos dice Palmer, las mujeres wichí tienen la suerte de desmentir el paradigma estructuralista que las asocia eternamente a la naturaleza. Pero esta disociación de las mujeres con la naturaleza inmediatamente después se revierte cuando el autor dice que existe una asociación entre ambas y esta sería la potente desocialización de la condición 
femenina, lo que las ubicaría, al menos por un momento, en el lado de la naturaleza. En este orden simbólico complementario las mujeres terminarán siendo descriptas como objetos pasivos de una agencia masculina activa: su sexualidad es domesticada y asociada a la maternidad para que produzcan hombres, la domesticación y el matrimonio son instrumentos para la defensa de los derechos masculinos en contra del matriarcado, los hombres forman a las mujeres para asignarles papeles culturales en el ámbito político y económico (ya que pueden ser cabezantes de una comunidad y deben procesar los productos masculinos -crudos - de la caza en el ámbito doméstico).

Ya por fuera de la exégesis del orden simbólico que Palmer construye y realiza, sus informantes (todos hombres) parecen quejarse de que sus mujeres han abandonado el ritual de iniciación y en consecuencia peligra la "función femenina" nodal que se les ha asignado en la cosmología y en la supervivencia cultural del grupo. Pero nada se nos dice acerca de las causas de este abandono, tampoco aparecen las voces de las mujeres comentando por qué dejaron progresivamente de practicar dicho ritual. Finalmente, habría que destacar la manera esencialista y primordialista de entender las identidades femeninas de las mujeres wichí, ya que aquí habría una única "identidad esencial" de "la mujer wichí" basada en las asociaciones simbólicas y los roles culturales asignados por un orden simbólico que, además de encontrarse bajo el poder de una agencia masculina (la de Palmer y posiblemente la de sus informantes al narrar), viene amenazando con dejar de existir (o simplemente con transformarse).

En la actualidad, la etnografía de Palmer y su análisis sobre el mito del origen y el antiguo ritual se han transformado en una de las principales fuentes de autoridad para otros autores. Barúa, Dasso y Franceschi (2008), en un artículo publicado en la primera compilación sobre mujeres indígenas en Argentina (Hirsch 2008), también sostienen que entre los wichí prevalecen relaciones de simetría y resguardo mutuo entre los géneros y las edades (2008, p.134):

Como se ha subrayado, existe una relación de simetría y de mutua atención respecto del género y la edad; ese dosificado equilibrio, presente en todos los mecanismos de aprendizaje-enseñanza (o, como ha sido definido, en el proceso de enhabilitación), y que se reencuentra puntualmente en los paradigmas míticos y en los parentales, sin embargo posee reglas precisas que hacen que pueda mantenerse constante el nivel de la buena voluntad (Barúa, Dasso y Franceschi 2008, p.137).

Si bien las autoras mencionan que los rituales de menarca son irregulares (2008, p. 133), realizan constantes afirmaciones acerca de los “...fundamentos mitológicos y cosmológicos de los fenómenos analizados, que son ciertos procesos y rituales que afectan particularmente el rol de la joven wichí" (2008, p. 119).

Montani (2008) analiza el lugar que tienen el tejido, sus productos y diseños para comprender las relaciones de género y la vigencia de categorías de género en la sociedad wichí (p. 155): “según la opinión de Alvarsson (1992, p. 3), las bolsas han ayudado, de esta manera, a mantener la autonomía y la autarquía que el rol femenino tradicionalmente ha tenido ante el masculino en la sociedad wichí (Métraux, p. 327)" (p. 170). Para Montani las mujeres ocupan una posición central en la sociedad wichí, demuestran un alto grado de poder y prestigio y encuentra evidencias para afirmar sus premisas en los trabajos de Alvarsson, Braunstein y especialmente en la etnografía de Palmer (2005), quién, según Montani:

... describió la concepción cosmológica desde la que se piensan las relaciones de género entre los wichí. Según este autor, ontológicamente, las mujeres son para los 
wichí seres de otra clase adheridos a una sociedad de hombres. El hecho se fundamenta en el mito de "El advenimiento de las mujeres" que relaté. (...) El carácter del género femenino como extranjero ontológico de este plano del cosmos queda manifiesto, entre otras cosas, en la existencia del rito de iniciación femenina y en la inexistencia de la contrapartida masculina" (Montani 2008, p. 173).

Hemos visto que el progresivo abandono del ritual de iniciación femenina en mujeres wichí no deja de ser reconocido por aquellas/os autoras/es posicionadas/os en una perspectiva cosmologicista. Cabe preguntarse, entonces, por qué este abordaje sigue teniendo presencia en la etnografía del Chaco. Las respuestas provisorias que encuentro son varias: cierta resistencia a conceptualizar los procesos de cambio sociocultural -a partir de la conversión al cristianismo en las misiones anglicanas- como producción de nuevas subjetividades e identidades y no meramente como pérdida de prácticas culturales (aculturación, asimilación, sincretismo); la imbricación y confusión entre el punto de vista nativo y el punto de vista (analítico) del/la antropólogo/a; el predominio de conceptos esencialistas y primordialistas para conceptualizar las identidades indígenas y de género que acaban por hiperculturalizarlos (o el "indio hiperreal" de Ana Ramos 1998), el lugar excepcional que tuvieron los rituales y la mitología en las etnografías de género de Amazonía y Melanesia (Gregor y Tuzin 2001), en las cuales el hecho de que tales rituales hayan dejado de practicarse hace décadas reviste de muy poca importancia en la mayor parte de los trabajos.

Pero creo que una respuesta central es que estos/as antropólogos/as tienen plena confianza en que los principios de visión y di-visión de las cosmologías wichí y qom siguen siendo determinantes en las formas de conciencia social de sus interlocutores, dada la vigencia de las lenguas wichí y qom en la socialización cotidiana de las personas. $\mathrm{Y}$, si bien es cierto que en las comunidades rurales del oeste formoseño y del nordeste salteño (Chaco centro-occidental) las lenguas indígenas muestran una increíble vitalidad, también suele suceder que las personas de estas comunidades - cuando dialogan con antropólogos/as que llegan a sus comunidades y, a pedido de estos/as- describen el tipo de prácticas y representaciones que recogería y analizaría un/a antropólogo/a interesado en estos temas, y tienden a ubicarlas en un tiempo pasado precristiano al que llaman en español "el tiempo de los antiguos". También suelen indicar que este tipo de "creencias" y "costumbres" (representaciones y prácticas) ya no son tan comunes, indicando que hay personas que muestran una "creencia" ambivalente en torno a las mismas (creer y no creer) para después mencionar "el trabajo que hicieron los misioneros" en "la cultura" de sus antepasados (Gómez, Greco y Torres Agüero 2013). Los/as propios/as indígenas son muy conscientes del carácter no inmutable de sus culturas y de la ambigüedad que sostienen ante las "creencias" que les transmitieron sus abuelos/as.

Aun así, la mirada cosmologicista parece darle más peso a los relatos y narrativas en donde la causalidad de los fenómenos y de su existencia responde a las lógicas del pensamiento mítico, animista, no naturalista (Descola 2001). Sin embargo, muchos/as indígenas (incluyendo a las personas ancianas) desde hace décadas se encuentran insertos en un diálogo permanente con esas "antiguas" explicaciones animistas y míticas de las cosas, contraponiéndolas a las explicaciones naturalistas o modernas que han integrado a lo largo del siglo XX y XXI en el marco de los procesos de conversión socio-religiosa y cultural acelerados, que vivieron a partir del trabajo asalariado en las agroindustrias de la región y la llegada de las misiones anglicanas y pentecostales. 
30 A diferencia de los trabajos sobre mujeres wichí, aquellos centrados en analizar la estructura simbólica de género en grupos qom intentaron construir una perspectiva de análisis más dinámica que diera cuenta de cómo al mismo tiempo que el ritual de iniciación dejó de practicarse, ciertos esquemas míticos todavía operan en los habitus y representaciones de las mujeres. En general, todas las autoras que abordamos estas cuestiones coincidimos en señalar que todavía hay elementos de una vieja ideología de género que circula en las comunidades y que advierte sobre los peligros y cuidados en los que aún hoy las mujeres deben educar a sus cuerpos, controlando sus fluidos polutivos y sus potencias transgresoras. En general, todas le hemos dado lugar al nivel de análisis estructuralista-simbólico (apoyándonos en el mito de origen de las mujeres, en el antiguo ritual de iniciación, y en el caso de Tola también en los fluidos corporales), al menos para inicialmente mapear el tipo de asociaciones simbólicas y valoraciones asignadas a cada género. Y coincidimos todas en visualizar en el mito sobre el origen de las mujeres, un canal para expresar intensos deseos de dominación masculina.

31 Tola, analizando los significados que los tobas del este les asignan a los humores corporales, en sus primeros trabajos encontraba que tanto en el mito sobre el origen de la menstruación como en la teoría sobre el proceso reproductivo, el accionar del hombre y su semen eran representados como el principio dominante dando por resultado una inscripción simbólica de la hegemonía masculina en el cuerpo de las mujeres (1999, p. 217). Así el mito toba acerca del origen de la menstruación expresaría "el temor masculino hacia las mujeres" y su fertilidad (Tola 2001a, p. 87) aunque advertía que los significados de los mitos y las ideas dominantes eran objeto de disputa, con lo cual insertaba la dimensión ideológica en su perspectiva de análisis. ${ }^{4}$ Citro (2008) considera la discusión dada por Rita Segato (2003) acerca de la dominación masculina como una estructura simbólica-cognitiva transcultural, y señala que la fecundidad de las jóvenes menstruantes es objeto del control masculino y que tanto en el mito sobre el origen de las mujeres como el mito sobre el origen de la menstruación "los significantes masculinos ocupan el lugar de lo activo transformador", es decir, la instancia de interdicción que posibilita a las mujeres ser (2008, p. 54). Mi análisis (Gómez 2008) sobre el mito de origen de las mujeres también se basa en las teorizaciones de Segato y en la lectura de varios trabajos sobre sexualidades indígenas desde una perspectiva antropológica $\mathrm{y}$ psicoanalítica, y concluyo que dicho mito concentra otro valor fundamental: el acceso sexual a las mujeres (ordenando de manera simultánea en el plano simbólico la sexualidad dentro del orden social): los hombres son proveedores de comida y a cambio obtienen el derecho a sus vaginas, vaginas temidas por su poder de castración pero también deseadas por el placer que pueden dar. Las mujeres desean comida y a cambio deberán copular con ellos, también tienen deseo sexual pues hay mitos que hablan de ello pero en el mito sobre el origen de las mujeres el deseo sexual tematizado es el masculino, no el femenino.

Las diferencias se presentan al momento de conceptualizar el peso que tiene en la vida cotidiana de las mujeres el orden simbólico o estructura simbólica de género mítica, y si se trata de una misma matriz, estructura u orden simbólico de género que determina la conciencia social a pesar de los cambios socio-históricos y de conversión sociorreligiosa (Citro 2008; Tola 2008) o si es mejor hablar de imaginario de género, ya que estamos ante la imbricación de símbolos y asociaciones que provienen de distintos órdenes simbólicos y de distintos horizontes culturales pero entre los cuales parece haber algunos puntos en común (al menos en algunas asociaciones simbólicas) (Gómez 2016). 

mujeres qom del oeste formoseño, elegí centrarme en las "prácticas y representaciones" en torno a la menstruación, su vínculo con la construcción del género en el pasado y en el presente y con el proceso de salud-enfermedad-atención (Gómez 2006), buscando comprender algunos "problemas de salud" a los que se referían las mujeres durante mis visitas a las comunidades. Las personas de la comunidad de Vaca Perdida a las que entrevisté o con las cuales conversé al respecto, asociaban mis preguntas con cosas que "pasaban en el tiempo de los antiguos". Aun así, mis intereses disparaban una serie de reflexiones sobre los acelerados cambios socioculturales que habían experimentado en las últimas décadas, especialmente a partir de la intervención de los misioneros anglicanos. En aquel entonces busqué analizar estas tensiones tomando distancia de otras producciones etnográficas que seguían de manera insistente reconstruyendo el antiguo ritual e ignorando las condiciones actuales de vida y de interlocución de las mujeres. Concluí que la ritualización de la menarca se había replegado a la trastienda de los hogares y que ciertas representaciones y tabúes en torno a la sangre (esquemas de una vieja ideología de género) continuaban organizando percepciones y acciones entre las mujeres mayores que las más jóvenes desafiaban y cuestionaban. Lorena Córdoba (2008) y Cecilia Gómez (2010), quienes realizaron trabajo de campo en las mismas comunidades qom, aun desde enfoques cosmológicos, hicieron observaciones similares aunque le otorgan prioridad a los esquemas sociocosmológicos en la interpretación de estas experiencias.

Citro (2009), por su parte, analizó cómo en algunas comunidades qom del este formoseño el viejo ritual de iniciación ha devenido en uno nuevo, compartiendo ambos una matriz simbólica de género similar. Así la autora se centra en los festejos de cumpleaños de quince entre las jóvenes takshik como nuevas dramatizaciones del paso de estatus de jóvenes a mujeres. En estos eventos participan los padres de las jóvenes, pastores y fieles de las iglesias - para brindar prédicas y testimonios- acompañados por conjuntos musicales evangélicos. La autora, influenciada por los estudios previos de cambio socioreligioso (Miller 1975; Wright 2008; Ceriani Cernadas 2008) analiza la transformación cultural e histórica de las performances, los rituales y la corporalidad entre los/as qom y su conexión con la producción de nuevas identidades femeninas y masculinas.

El análisis estructuralista centrado en el simbolismo de género, se basa en la idea de que las categorías de género (hombre y mujer) son categorías simbólicas a las cuales se les suele asociar valores y expectativas culturales (Moore 1988). De este modo, se puede analizar el comportamiento ideal y los roles ideales asignados a cada género con los comportamientos y responsabilidades empíricamente observables. Moore agrega que el asunto con el que debe lidiar el análisis simbólico de género es cómo usamos este complejo y cambiante imaginario, para arribar a un entendimiento complejo de la posición de la mujer. Siguiendo este planteo, creo que el problema de los estudios mencionados entre qom y wichís es que sus autores no tratan a este orden simbólico como un imaginario complejo y cambiante, sino como una estructura estática que no se modifica. Pero en verdad las personas crean nuevas asociaciones en torno a estos constructos de género, los revisten de nuevos significados y valoraciones a través de las interacciones en la vida cotidiana, interacciones marcadas por desigualdades de poder y autoridad, resistencia, dominación, hegemonía, etc. 


\subsection{Omisiones sobre la desigualdad de género y escasas observaciones sobre violencia(s)}

análisis del orden simbólico de género, es que prácticamente no aporta datos etnográficos sobre la desigualdad de género en las comunidades indígenas del Chaco. A pesar de los análisis en torno a la ideología de domesticación de las mujeres, presente en los mitos y en el antiguo ritual de iniciación, suele plantearse que en los grupos wichí y qom las relaciones de género tienden a ser simétricas y complementarias (Palmer 2005; Mendoza 2002; Barúa et. al 2008). Así, pareciera que la ideología de dominación masculina legitimada en los mitos (y en la que podría leerse un acta antigua de legitimación de la desigualdad de poder y autoridad entre varones y mujeres, a causa del estado liminal y peligroso de las últimas) no tiene ningún tipo de anclaje cuando nos situamos en el presente etnográfico y observamos que, los de por sí escasos análisis sobre dinámicas del poder entre los géneros, quedan relegados a la esfera mítica del orden simbólico.

¿Se debe esto a la persistencia de una imagen romántica sobre los grupos indigenas? Probablemente, pues la imagen de libertinas sexuales y mujeres autónomas creada por los primeros etnógrafos de la región efectivamente decantó en los estudios posteriores. No obstante, el hecho de que las mujeres gocen (o hayan gozado en un pasado precristiano) con escasas constricciones para elegir con quién mantener una relación sexual o formar una familia no es una garantía para afirmar que allí, entonces y por derivación, existen relaciones igualitarias de género. La sexualidad, la reproducción, el poder y la autoridad son dimensiones interconectadas en cualquier sistema de sexo-género pero al mismo tiempo muestran grados de autonomía (Rubin 1986).

Una de las vías de acceso conceptual y empírica para indagar acerca de la igualdad/ desigualdad de género se apoya en el análisis de los rasgos de la organización social (la estructura social) y en la medición del acceso de las mujeres a roles de liderazgo igual o similares a los que ocupan los hombres. ${ }^{5}$ Pero siguiendo a Collier (1974), antes de medir esto habría que considerar en términos weberianos la diferencia entre poder y autoridad: mientras que existen formas de poder difusas que pueden ejercer hombres y mujeres, la autoridad implica la legitimidad social para ejercer poder (es decir, el derecho que depositan los miembros de un grupo en ciertos agentes para ejercer poder). Como sugieren las evidencias y análisis de varios trabajos, en los grupos indígenas del Chaco los liderazgos aparentemente siempre han estado en manos de los hombres, antes y luego de los procesos de conversión socio-religiosa y cultural (Cordeu y De los Ríos 1982, p. 166; Braunstein 1983, pp. 40-41; Mendoza 2002, p. 108; Palmer 2005, p. 96; Gordillo 2010). No obstante, en los últimos años en distintas comunidades del Chaco las mujeres han comenzado a participar en espacios usualmente monopolizados por los varones, como los proyectos de ONG, "la política" (de carácter partidario en municipios con alto porcentaje de población indígena) y la militancia en organizaciones indígenas. Esta es una discusión que recién comienza a abordarse en los estudios sobre las modalidades de participación política y los procesos organizativos de mujeres indígenas en la región del Chaco (Hirsch 2003; Castelnuovo 2010; Sciortino 2013, 2015; Gómez 2014).

Considerando el caso de los grupos qom (del oeste), Mendoza (2002) afirma que no existía un liderazgo femenino semejante al que mostraban los hombres en la guerra (líder guerrero), la jefatura de banda o el chamanismo (piogonaq), pero las mujeres de los líderes 
de banda (jaliaganá) influían en otras mujeres y contribuían al mantenimiento de relaciones igualitarias entre las bandas. ${ }^{6}$ Hoy en día ocurre lo mismo con las esposas de los referentes comunitarios, representantes y líderes políticos. Respecto al liderazgo religioso, Métraux (1980, p.90) afirmaba que las mujeres qom y mataco (wichí) eran chamanes "en raras ocasiones". En su etnografía con los qom del oeste y los pilagá realizada a partir de dos estancias durante la década de 1930, al discutir aspectos de la autoridad señalaba que en ninguna ocasión las mujeres ejercían mando ya que según sus interlocutores varones ellas carecían de coraje (1980[1933], p. 41). Sobre el liderazgo entre los grupos wichí con los que convivió (y convive) Palmer, se señala que solo algunas mujeres pueden desarrollar liderazgo como cabezantes (niyat) aunque su influencia política generalmente se limita al ámbito doméstico (2005, p. 96).

Uno de los escasos análisis antropológicos en el Gran Chaco, donde se discutió explícitamente la violencia de género, ha sido el de Stephen Kidd (1995) sobre la violencia doméstica entre los enxet del Chaco paraguayo. Este autor planteaba que la violencia contra las mujeres se debía a la influencia de la sociedad blanca y de su ideología machista en los hombres, argumentando que la violencia no existía en las relaciones de género propiamente indígenas. Influenciado por los argumentos de Overing (1986) para Amazonía, reivindicaba el paradigma de la complementariedad para comprender las originales relaciones de género entre los enxet que se habían visto corrompidas por el mundo blanco y mestizo. ${ }^{7}$ Otro artículo es de mi autoría (Gómez 2008) y allí analicé la amenaza de la violencia sexual - naturalizada - con la que conviven las mujeres qom del oeste formoseño y las estrategias que tienen para lidiar con ella cuando deben salir al monte a recolectar. A mi modo de ver y de analizar, los fundamentos y argumentos que en la actualidad permiten legitimar este tipo de amenaza (de violencia simbólica que podía convertirse en violencia sexual), se encontraban en el antiguo orden simbólico de género (mítico) y en el cristiano. Es decir, en el imaginario de género actual.

\section{Un abordaje alternativo a la mirada cosmologicista: procesos de subjetivación, habitus e historias de vida}

41 En mi investigación con las mujeres qom del oeste formoseño (Gómez 2016) el objetivo central que me propuse fue analizar las transformaciones en la construcción cultural del género femenino a partir del proceso de conversión socio-religiosa al anglicanismo iniciado en 1930. La variable temporal, por lo tanto, devino central dado que me interesaba comprender qué características tenía la posición social de las mujeres en el pasado precristiano (es decir, en el sistema de sexo-género matrilocal con ideología patriarcal, Gómez 2016b), cómo se transformó en el marco del proceso de misionalización anglicana, qué continuidades y rupturas se produjeron respecto de las prácticas y valores enmarcados en el antiguo sistema de sexo-género y qué clase de reflexiones elaboran las propias mujeres sobre estas cuestiones. ${ }^{8}$ Sería bastante desafortunado negar que la llegada de los misioneros anglicanos y el proceso de conversión socio-religiosa representan un punto de inflexión en la historia oral de los tobas del oeste en el siglo XX (Gordillo 2010). El proceso de misionalización anglicana (al igual que el pentecostal entre los qom y wichís del chaco oriental) fue una bisagra cultural o un proceso en torno al cual las y los tobas no terminaron de reflexionar aún (de dónde vienen, quiénes son, hacia donde van), es decir que actualmente están elaborando sus propias identidades como sujetos sociales aborígenes $\mathrm{y}$, a menudo, este trabajo lo realizan desde un imaginario social 
colonizado por esquemas de visión cristianos y atravesados por el binomio civilización/ barbarie (Wright 2003). Las referencias al pasado precristiano (la vida de los antiguos), a la vida en la misión y a la vida presente o la vida de los nuevos ${ }^{9}$-marcada por pautas de escolarización, sedentarización, dinámicas de la política partidaria y la agencia de proyectos de desarrollo del Estado y de $\mathrm{ONG}-$, son cuestiones muy pero muy recurrentes en sus conversaciones.

En razón de esto, mi punto de partida fue visibilizar a las mujeres qom como sujetos culturales híbridos y complejos, cuyas identidades y subjetividades están atravesadas por tensiones, antagonismos y sincretismos como resultado de los procesos de conquista, semiproletarización y conversión socio-religiosa que, desde lógicas de poder disciplinarias y pastorales, modificaron las lógicas de sociabilidad y los habitus indígenas a través de las últimas cuatro generaciones. Así, me apoyé en los estudios ligados a la tradición marxista-gramsciana (Trinchero y Maranta 1987; Gordillo 2006, 2010) y en aquellos centrados en analizar los cambios socio-religiosos que entienden que la presencia de las misiones en la región del Chaco deben ser pensadas como un conjunto de procesos civilizatorios constructores de modernidades periféricas (Cordeu y Siffredi 1971; Miller 1975; Torres-Fernández 2006; Wright 1983, 1988, 2008; De la Cruz 1989; Citro 2009; Ceriani Cernadas 2008). Tales investigaciones comprendieron a las subjetividades de los indígenas como híbridas, contradictorias y complejas, no orientadas de manera primaria y esencial hacia un único discurso cultural (como el de las cosmologías nativas), y que vienen desarrollando sus vidas en geografías periféricas y poscoloniales del Chaco argentino.

Siguiendo lo anterior, comencé la investigación (habiendo trabajando previamente en las comunidades como técnica social en proyectos de ONG locales) asumiendo que ni las narrativas míticas, ni una supuesta cosmología qom como forma de conciencia indígena inalterable al paso del tiempo, ni el antiguo ritual de iniciación poseen el monopolio del discurso sobre el género. Mi punto de partida teórico sobre el género implicó incorporar una perspectiva dinámica, histórica y feminista postestructuralista sobre la construcción cultural del mismo. ${ }^{10}$ Esta parte de considerar los cambios en los roles, prácticas, estereotipos, disposiciones corporales y espaciales, responsabilidades o prescripciones y asociaciones simbólicas con las que se encuentra (y sobre las que produce significados) un sujeto social (mujer, varón u otro género) a lo largo de su vida o en un período de su vida y en relación a las modificaciones económicas, culturales y sociales de su entorno; también la consideración de que las personas no se ven interpeladas, situadas o subjetivadas por los discursos y prácticas de género de igual manera en diferentes momentos de su ciclo de vida. La relación de una mujer con los significados respecto de lo femenino se modificarán durante el curso de su vida, y tales significados se irán articulando con otras variables que demarcan su experiencia.

Siguiendo a Moore (2007, p. 19), “...las identidades de género no están determinadas por modelos culturales como antes sugerían los antropólogos, ni por un momento definitivo en la adquisición de la identidad sexual como los psicoanalistas proponían", y a Lamas (2000) cuando plantea que la asimilación del género femenino o masculino se logra mediante un proceso gradual de socialización e inmersión en los patrones femeninos y masculinos de determinado grupo social, busqué en mi investigación trascender la perspectiva etnográfica cosmologicista y elaborar otra donde el énfasis estuviera puesto en mapear los procesos de subjetivación en el orden del género (pero en relación con otras variables) de los que fueron objeto las mujeres qom a lo largo de su ciclo de vida. 
Esto no significó dejar de lado el análisis simbólico (el análisis de asociaciones simbólicas en torno a la categoría mujer que todavía persisten en representaciones, discursos y situaciones); por el contrario, me interesó integrarlo pero tan solo como un nivel más del análisis y mostrando cómo el orden simbólico que comparten los y las qom es en verdad un dominio variable, ${ }^{11}$ dinámico y bastante caótico en donde coexisten y se superponen asociaciones simbólicas y significados culturales provenientes de la antigua ideología de género qom, de la ideología de género cristiana y de la ideología de género de la modernidad. Esta última legitima un grado mayor de autonomía de las personas (y en especial de las mujeres) y un proceso de individuación en varias dimensiones de la vida que, para el caso de aquellas mujeres qom asalariadas, suele traducirse en una ruptura con las lógicas de parentesco de su familias (y, en consecuencia con ciertas expectativas de las mujeres para con el matrimonio, la sexualidad, la reproducción, el trabajo doméstico) y en el cuestionamiento sobre ciertos estereotipos femeninos y masculinos.

Una vez que analicé y comprendí los cambios que trajo el proceso de misionalización anglicana en la vida de las mujeres (y varones) y en su posición social, me situé en el presente y elaboré una hipótesis: en la actualidad existen tres modelos de feminidad toba o qom o tres formas de "ser-mujer" en las comunidades tobas a las que se podría situar en dos colectivos generacionales distintos. Esta hipótesis se basó en observaciones previas: durante los años que trabajé en dichas comunidades pude notar diferencias significativas entre ellas, manifiestas en síntesis corporales-espaciales-narrativas distintas que en términos analíticos podrían definirse como habitus femeninos. ${ }^{12}$ Esta hipótesis ha operado como un punto de partida para interrogarme sobre las prácticas de subjetivación $\mathrm{y}$ formas de sociabilidad que posibilitaron tales diferencias.

46 Tales procesos de subjetivación en el orden del género ${ }^{13}$ los reconstruí mediante el análisis de historias de vida que realicé a 9 mujeres, proponiéndome mostrar cómo la construcción cultural del género de las mujeres qom se produjo no asintiendo a modelos simples de feminidad que se asumen en un único momento de la vida (en el ritual a la llegada de la menarca por ejemplo), sino en el entramado de relaciones sociales en las que se fueron vinculando desde pequeñas, en la asignación de roles, responsabilidades, actividades y estereotipos que les asignan discursos normativos de género cristianos, qom y modernos que ellas se apropian, reelaboran, critican y resisten.

47 Una historia de vida es un relato narrativo y autobiográfico solicitado, producido por alguien para otra persona en un contexto determinado, con características altamente reflexivas por parte de quien narra. Siguiendo los planteos de varios autores (Lagnes y Frank 1981; Linde 1993; Saltalamacchia 1992; De los Ríos 1976/80; Ceriani Cernadas 2008), en mi investigación utilicé estos relatos de vida como un recurso y un artificio ${ }^{14}$ para conocer no solo la relación imaginaria que las personas, en este caso mujeres qom, construyen respecto de sí mismas y sus biografías personales y familiares, sino que también pude entrever y reconstruir las relaciones significativas en las que mis interlocutoras se involucraron en el pasado: quiénes las alimentaron y criaron cuando eran niñas, cómo ha sido su vinculación con la escuela (misional y estatal), qué sucedió a la llegada de su primera menstruación y qué cambios y continuidades mostraba esta experiencia con la forma ritualizada en la que se la celebraba en el pasado, de qué formas experimentaban las tensiones espaciales y sexuales que se destacan en los relatos sobre su juventud, cómo ingresaron en la vida conyugal y comenzaron a tener niños y qué vínculos han forjado con el trabajo doméstico y con la maternidad. En la medida en que las mujeres fueron recreando estas historias siguiendo el orden ascendente de su ciclo vital, 
también marcaron rupturas y continuidades con "el pasado de los antiguos" (el tiempo pasado que reconstruí en la primera parte de la investigación mediante al análisis de los documentos anglicanos), permitiéndome detectar cambios en las relaciones, roles, estereotipos, prácticas, normas y asociaciones simbólicas en torno al género femenino.

El análisis de las historias de vida reveló que las mujeres no se guían meramente por un orden simbólico de origen cosmológico qom, pues el imaginario social para reconstruir, significar y evaluar sus experiencias pasadas y presentes, tanto como para definirse ellas mismas y a otras mujeres, anuda representaciones sobre el mundo femenino que provienen de distintos discursos. Por un lado, tenemos las narrativas míticas que, enraizadas en la vieja ideología de género (aquella que seguían los antiguos) advierten sobre los peligros y cuidados que deben mantener con sus cuerpos, fluidos y potencias, especialmente a la llegada de la menarca, e insisten en mantener el vínculo de las mujeres con las prácticas de recolección. Por otro lado, las mujeres se han apropiado del discurso cristiano que resalta la moral sexual femenina, la domesticidad y la maternidad, creando jerarquías que las dividen a partir de su moral sexual y familiar. Por último, algunas pocas mujeres suman un discurso más moderno que, sin abandonar los lugares comunes que el anterior asigna a las mujeres, les permite criticar las desigualdades que existen en las comunidades y otorgarle importancia a la educación y a la autonomía económica individual para el "progreso" de ellas y de sus familias. En síntesis, mis interlocutoras muestran una variedad de posiciones de sujeto, irreductibles a un único discurso cultural sobre el género, la sexualidad y la feminidad como parecía existir en el pasado precristiano de las primeras décadas del siglo XX. El imaginario de género al que recurren las mujeres para narrar sus historias de vida toma símbolos y significados que provienen del orden simbólico mítico, del cristiano y del moderno.

Por otra parte, y situándonos en las prácticas de socialización antiguas y en las rupturas y continuidades en el presente, habría que señalar que con respecto al parentesco, el análisis revela la persistencia de la matrilocalidad, la participación de las mujeres en las decisiones conyugales de sus hijas/os y nietos/as, la imposición de matrimonios o los matrimonios forzados, prácticas en torno a tabúes y prescripciones -elementos del antiguo ritual de iniciación femenina- así como la existencia de una política cultural de género que encarnan y transmiten las mujeres mayores hacia las más jóvenes. Del lado de los cambios habría que mencionar, en primer lugar, el alto grado de conciencia que tienen las y los qom sobre los cambios culturales y religiosos que trajo a sus vidas la presencia de los misioneros anglicanos durante más de cinco décadas. $Y$, en segundo lugar, nuevos espacios, relaciones sociales, lógicas y tiempos pastorales y disciplinares; mientras que a las antiguas relaciones y lógicas culturales se les asignaron nuevos significados a partir del discurso cristiano anglicano presente en las nuevas formas de socialización impuestas durante la vida en la misión. También cabría resaltar el movimiento entre geografías diversas interconectadas (el monte, la misión, los ingenios, los obrajes, el pueblo) y lugares (la casa, la misión, la iglesia, el monte, la escuela). La vida en el pueblo y la permanencia prolongada en la escuela promueven la identificación con hábitos de vida que los tobas reconocen como "criollos" o "acriollados". Ese estilo de vida y la posibilidad de acceder a un cargo o empleo público también promueven la ruptura con el habitus rural de los indígenas de la región, especialmente en las mujeres es notorio el proceso de individuación (modernización) de ciertas dimensiones de la persona, como la reproducción mediante el control de la natalidad, la conyugalidad mediante el establecimiento de relaciones autónomas con los hombres -independientemente de si 
ello se ve acompañado de nuevas formas de violencia de género-, la maternidad como un proyecto personal o de la pareja, entre otras. Las categorías tempo-espaciales (que también funcionan como marcadores generacionales) con las que los/las tobas narran y construyen su pasado y presente podrían ser: el tiempo de los antiguos, la vida en el tiempo del río y de la misión, el tiempo de los nuevos, la vida después de la inundación, el tiempo de la política, el tiempo de la organización, entre otros.

50 En resumen: en las comunidades indígenas del Chaco argentino (cualquiera que se acerque a una de ellas podrá comprobarlo) el viejo ritual de iniciación y los mitos ya no posee el monopolio del discurso sobre el género y la sexualidad, pues existen otras prácticas discursivas disponibles en estos contextos. El punto en cuestión es si nuestros modelos de acercamiento a la construcción social y cultural del género las incorporan o no, y ello dependerá de los presupuestos que manejamos, capaces de depositar una mayor o menor alteridad sobre los grupos indígenas con los que trabajamos. De este tipo de elecciones en torno al grado de alterización y exotización que construimos en nuestras aproximaciones etnográficas dependerá la posibilidad de crear análisis que privilegien preguntas en otras direcciones: ¿qué lugar tienen los mitos y los antiguos rituales en los contextos indígenas actuales donde tales dispositivos se han transformado? Y, si es así, ¿cómo permanecen? ¿Podemos obviar este dato y dedicarnos a reproducir análisis solo a un nivel simbólico estructural del género?

\section{Palabras finales}

51 A lo largo de este artículo elaboré una crítica a la mirada cosmologicista sobre el género de las mujeres indígenas del Chaco señalando varias debilidades, entre ellas, su ahistoricidad dado que prioriza solo el nivel estructuralista de análisis, sin integrar la dimensión sociológica del género, la dimensión imaginaria de las personas con el antiguo orden simbólico, todo lo cual conduce a eternizar la condición etnológica de las mujeres en la ideología de género que expresan los viejos mitos y el antiguo ritual de iniciación femenina.

52 Para ir cerrando, cabe recordar que "cosmología" es una categoría de análisis (como clase social, género o etnia) y no un fenómeno empírico en sí mismo. Como tal, refiere a la conceptualización del ordenamiento del mundo y de sus componentes que se representan los miembros de un grupo social o de una cultura, también hace referencia a un sistema de conocimiento con supuestas dimensiones filosóficas, culturalmente organizado, donde ciertas categorías como espacio, tiempo, persona, lo otro, etc., serían claves. En suma, se trataría de una visión integrada del mundo y del universo, de sus espacios, de sus dimensiones y de las relaciones entre los componentes que se reconocen como formando parte de una definición del cosmos: personas humanas, animales, seres no-humanos, plantas, árboles, ríos, aguadas, montañas, etc. (Hill y Mannheim 1992). Así, siguiendo los planteos de estos y otros autores (Godelier 1990; Sahlins 1988), la cosmología como categoría permite elaborar un mapa conceptual o una totalidad ordenada según una lógica particular que reconstruyen los/las antropólogos/as partiendo de datos etnográficos: dispositivos visuales, entrevistas y narrativas que le cuentan sus interlocutores durante sus trabajos de campo.

Sin embargo, tal como se la viene utilizando en algunas etnografías del Chaco (aquí estoy dejando de lado las elaboraciones que pueden hacer las organizaciones indígenas al reivindicar derechos territoriales apelando a conceptos como cosmología o cosmo- 
política) produce una representación de los miembros de los pueblos indígenas como sujetos ontologizados de manera esencial en ontologías indígenas cuyos principios de visión y di-visión son tratados teóricamente como inmanentes y transhistóricos, sobre los cuales se superpondrían, a la manera de principios ontológicos segundos o residuales, el resto de los principios que orientan las prácticas forjadas en contacto con otras ontologías (si por un momento nos permitimos ver un tipo de "ontología moderna" en los proyectos de civilización y modernización de los que fueron objeto los indígenas de las provincias de Formosa y Chaco desde las primeras décadas del siglo XX) (Citro y Gómez 2013). Desde mi punto de vista, la imagen general que puede reconstruirse a partir de la mirada cosmologicista sobre el género de las indígenas del Chaco remite al pasado preconquista y precristiano y a lo que podríamos denominar mejor como arquecosmologías. Pues las/los indígenas son sujetos híbridos en términos culturales y religiosos encontrándose subjetivadas/os hacia los esquemas ontológicos de visión y di-visión de sus grupos de origen, del cristianismo con particular énfasis y de la modernidad periférica de las localidades donde los pueblos indígenas del Chaco fueron reterritorializados, alterizados y subalternizados por los estados provinciales y otras fuerzas hegemónicas.

Por otra parte, cosmología y ontología son conceptos que conllevan la impronta de los modelos cognitivistas y representacionistas que, siguiendo la crítica planteada por Csordas (1999), tienden a ubicar el saber cultural en la representación y en la autorreflexión de los indígenas, describiendo la cultura de otros en términos de esquemas, modelos y categorías nativas y mucho menos como práctica incorporada o corporificada: embodiment (Csordas, 1993) y habitus (Bourdieu 1991), es decir, como un tipo de conocimiento entendido como un producto histórico de formas específicas de circulación y transmisión de saberes - muchas veces en un estado no objetivado- dentro de un grupo signado por diferencias de género, generacionales, de clase y étnicas.

Por último, el uso conceptual de cosmología está ligado a un viejo concepto de cultura, arrastrando presupuestos que fueron ampliamente cuestionados en la antropología, tales como la homogeneidad y uniformidad de las creencias y prácticas compartidas, las lógicas sistemáticas y coherentes y la creación arbitraria de límites culturales (Wright 1998; Crehan 1996, p. 129). Tal vez sería mejor repensar la cosmología como un "discurso autorizado" producido en circunstancias particulares por ciertos individuos de las comunidades donde investigamos pero que otros miembros de esas mismas comunidades bien pueden cuestionar (Asad 1973 en Wright 2004). En esta misma línea de razonamiento, Godelier planteaba que el problema (antropológico) con las creencias y prácticas de una cosmología no podría reducirse a explicar - en tanto observadores externos- cómo los miembros de una sociedad comparten o no las creencias tenidas por verdaderas “... sino que debe explicarse cómo en una misma sociedad, en la misma época, ciertas ideas tenidas por verdaderas por la mayoría de los miembros son consideradas falsas por diversas minorías" (1990, p. 77$) \cdot{ }^{15}$ Quienes hicimos trabajo de campo en comunidades del Chaco argentino hemos escuchado y visto cómo los/las propios/as indígenas suelen cuestionar la lógica de las creencias, prácticas y el tipo de experiencias que tenían los antiguos (así es como denominan a sus antepasados cuando todavía no se habían convertido al cristianismo) al compararlas con las prácticas que fueron incorporando las nuevas generaciones (a los que llaman los nuevos) en las últimas décadas, en el marco de los procesos de semiproletarización, conversión socio-religiosa, escolarización y participación en políticas estatales de asignación de recursos y empleo. 

Sahlins (1988) ${ }^{16}$ y especialmente Godelier (1990) en Lo ideal y lo material. Aquí este autor se preguntaba: “... ¿ ¿es ideología lo equivalente a 'falsa conciencia', 'representaciones ilusorias que los hombres se forman de ellos mismos y del mundo, y que legitiman un orden social nacido sin ellas (...)?" (p. 78). Y también si “¿habría que considerar ideológicas las representaciones que legitiman las relaciones sociales y no ideológicas las que lo organizan?" (1990, p. 78).

Independientemente de lo anterior, aquí consideramos que las prácticas cotidianas de los miembros de los pueblos indígenas no están orientadas de manera esencial y primaria hacia los principios ontológicos de sus lenguas y culturas. Los/las indígenas del Chaco argentino interaccionan socialmente desde habitus complejos e híbridos que están compuestos por principios de visión, acción y percepción que provienen de horizontes culturales distintos y de los cuales la etnografía, hasta ahora, dio cuenta de manera separada, sea desde la perspectiva ontologicista o cosmologicista, desde la perspectiva del cambio socio-religioso o desde una perspectiva que optó por centrarse en los antagonismos y las tensiones producto de la proletarización, la misionalización y la ciudadanización subalternizada de los pueblos indígenas. Este habitus o ser-en-el-mundo híbrido está compuesto por antiguos principios, manifiestos en la persistencia de lógicas de acción que provienen de la praxis y estructura social antigua (todavía presente en el parentesco, en las reglas de residencia posmarital, en la división sexual del trabajo y otras dimensiones), y también (pero no superpuestos arriba de los primeros, como si se tratara de una simple lógica mecánica) por principios de visión, percepción y acción que llegaron con la instalación de proyectos de conversión socio-religiosa en el marco de la implantación de una economía capitalista en la región del Chaco. En conclusión: sus subjetividades están atravesadas por varios antagonismos y tensiones (Gordillo 2006); entre estas, aquella entre lógicas sociales que hunden sus raíces en la antigua praxis indígena y lógicas sociales modernas que se vuelven manifiestas en procesos de individuación que viven las personas y las familias en diversas dimensiones como el trabajo, el género, la familia, la sexualidad y la reproducción y que modifican sus formas de sociabilidad (Gómez 2013).

Barúa, G. (1994). Parentesco de coral: adopción y alianza entre los mataco-wichí. Actas del Primer Congreso Argentino de Americanismo, 2, 95-110.

Barúa, G. (1998). Las normas matrimoniales en la práctica wichí. Actas del Segundo Congreso de la Sociedad de Americanistas, 1, 97-124.

Barúa, G. (2007). Un arte delicado. Relaciones entre el parentesco, el conflicto y el acontecimiento entre los wichí del Chaco Central. Buenos Aires: Dunken.

Barúa, G. y Dasso, C. (1999). El papel femenino en la hostilidad wichí. En M. Califano (Ed), Mito, guerra y venganza entre los wichí (pp. 251-298). Buenos Aires: Ciudad Argentina.

Barúa, G., Dasso, C. y Franceschi, Z. A. (2008). El papel femenino en la convivencia wichí del Chaco Central. En S. Hirsch (Coord.), Mujeres Indígenas en la Argentina. Cuerpo, Trabajo y Poder (pp. 117-152). Buenos Aires: Biblos.

Bourdieu, P. (1986). Notas provisionales para la percepción social del cuerpo. En AA.VV., Materiales de sociología crítica (pp. 183-194). Madrid: La Piqueta.

Bourdieu, P. (1991). El sentido práctico. Madrid: Taurus. 
Bourdieu, P. (2006). Argelia 60. Estructuras económicas y estructuras temporales. Buenos Aires: Siglo XXI.

Braidotti, R. (2000). Sujetos nómades. Corporización y diferencia sexual en la teoría feminista contemporánea. Buenos Aires: Paidós.

Braunstein, J. (1974). Matrimonio y familia entre los mataco. Cuadernos Franciscanos, 35, 72-79.

Braunstein, J. (1983). Algunos rasgos de la organización social de los indígenas del Gran Chaco. Trabajos de Etnología, 2, 13-107.

Butler, J. (2002). Cuerpos que importan. Sobre los límites materiales y discursivos del "sexo". Buenos Aires: Paidós.

Candau, J. (2001). Memoria e identidad. Buenos Aires: Ediciones del Sol.

Castellanos, G. (2008). Serialidad, dominación, performatividad: la construcción de las identidades subordinadas y la aceptación de la subordinación. En P. Wade, F. Urrea Giraldo y M. Viveiros Vigoya (Coords.), Raza, etnicidad y sexualidades: ciudadanía y multiculturalismo en América Latina (pp. 513-539). Bogotá: Universidad Nacional de Colombia, Facultad de Ciencias Humanas, Centro de Estudios Sociales (CES), Escuela de Estudios de Género.

Castelnuovo, N. (2010). La participación política de las mujeres guaraníes en el noroeste argentino. Boletín de Antropología, 24 (41), 223-241.

Ceriani Cernadas, C. (2008). Nuestros hermanos Lamanitas. Indios y fronteras en la imaginación mormona. Buenos Aires: Biblos.

Citro, S. (2008). Creando una mujer: ritual de iniciación femenina y matriz simbólica de los géneros entre los qom takshik. En S. Hirsch (Coord.), Mujeres Indígenas en la Argentina. Cuerpo, Trabajo y Poder (pp. 27-58). Buenos Aires: Biblos.

Citro, S. (2009). Cuerpos Significantes. Travesías de una etnografía dialéctica. Buenos Aires: Biblos.

Citro, S. y Gómez, M. (2013). Perspectivismo, fenomenología cultural y etnografías poscoloniales: intervenciones en un diálogo sobre las corporalidades. Espacio Amerindio, 7(1), 256-286.

Collier, J. (1974). Women in Politics. En M. Z. Rosaldo y L. Lamphere (Eds.), Women, Culture and Society (pp. 89-96). California: Standford University Press.

Collier, J. y Rosaldo, M. (1981). Politics and gender in simple societies. En S. Ortner y H. Whitehead (Eds.), Sexual Meanings. The cultural construction of gender and sexuality (pp. 275-329). Cambridge: Cambridge University Press.

Cordeu, E. y De los Ríos, M. (1982). Un enfoque estructural de las variaciones socioculturales de los cazadores recolectores del Gran Chaco. Suplemento Antropológico, XVII (1), 147-160.

Cordeu, E. y Siffredi, S. (1971). De la Algarroba al Algodón. Movimientos Milenaristas del Chaco Argentino. Buenos Aires: Juárez.

Cordoba, L. (2008). ¿Existe la iniciación? Procesos de construcción social de la feminidad entre los toba del oeste formoseño. Acta Americana, 16(2), 61-83.

Crehan, K. (2002). Gramsci, Cultura y Antropología. Barcelona: Bellaterra.

Csordas, T. (1999). Embodiment and Cultural Phenomenology. En G. Weiss and H. Haber (Eds.), Perspectives on Embodiment (pp. 143-162). New York: Routledge.

Csordas, T. (1993). Somatic modes of Attention. Cultural Anthropology, 8(2), 135-156. 
Dasso, C. (2006). Condición y entidad de los liderazgos wichí. En J. Braunstein (Ed.), Liderazgo, representatividad y control social. Resistencia: UNNE, e/p.

De la Cruz, L. M. (1989). Apuntes para la reconstrucción historiográfica de las iglesias no católicas en el Gran Chaco. Actas de las X Jornadas regionales de Geohistoria Regional, pp. 70-84.

De los Ríos, M. (1976-80). Una historia de vida. Notas para la hermenéutica del ciclo vital en la etnia mataco. Runa, XIII (1 y 2), 70-112.

Descola, P. (2001). Construyendo Naturalezas. Ecología simbólica y práctica social. En P. Descola y Gisli Parson (Comps.), Naturaleza y Sociedad. Perspectivas Antropológicas (pp. 101-123). México: Siglo XXI.

Godelier, M. (1990). Lo ideal y lo material. Pensamiento, economías, sociedades. Madrid: Taurus.

Gómez, C. (2010). La luna y la feminidad entre los qom del oeste formoseño (Gran Chaco, Argentina). Campos, 1(1), 47-64.

Gómez, M. (2006). Representaciones y prácticas en torno a la menstruación y menarca entre mujeres qom: entre la salud de las mujeres y la construcción social del género femenino. Papeles de Trabajo, 14, 9-51.

Gómez, M. (2008). El cuerpo por asalto. La amenaza de la violencia sexual en el monte entre las mujeres tobas del oeste de Formosa. En S. Hirsch (Coord.), Mujeres Indígenas en la Argentina. Cuerpo, Trabajo y Poder (pp. 79-116). Buenos Aires: Biblos.

Gómez, M. (2013). Modernidad y Género en mujeres indígenas tobas (qom) del Chaco centrooccidental, Argentina: algunas reflexiones. En J. Gregor-Ströbele y D. Wollrad (Coords.), Espacios de Género: Adlaf Congreso Anual 2012 (pp. 288-301). Buenos Aires: Nueva Sociedad; Fundación Friedrich Ebert; Adlaf.

Gómez, M. (2014). Mujeres indígenas en Argentina: espacios fugaces para nuevas prácticas políticas. Publicar en Antropología, 12(16), 59-81.

Gómez, M. (2016a). Guerreras y Tímidas doncellas del Pilcomayo. Las mujeres qom (tobas) del oeste de Formosa. Buenos Aires: Biblos.

Gómez, M. (2016b). Las mujeres también luchan: Una "política sexual" desde los cuerpos entre las mujeres qom (tobas del oeste) antes de la conversión socio-religiosa (Chaco centro-occidental). (En prensa).

Gómez, M., Greco, L. y Torres Agüero S. (2013). Bailar como los antiguos: silencios, memoria y corporalidad entre jóvenes, mujeres y maestros bilingües del Barrio Toba de Ingeniero Juárez. X RAM. Reunión de Antropología del MERCOSUR, Córdoba.

Gómez, M. y Sciortino, S. (2015). Mujeres indígenas, derechos colectivos y violencia de género: Intervenciones en un debate que inicia. Revista Entramados y Perspectivas de la carrera de Sociología, 5 (5), 37-63.

Gordillo, G (2006a). El Gran Chaco en la historia de la antropología argentina. En G. Gordillo (Comp.), En el Gran Chaco. Antropologías e Historias (pp. 225-254). Buenos Aires: Prometeo Libros.

Gordillo, G. (2006b). Hermenéutica de la ilusión. En G. Gordillo (Comp.), En el Gran Chaco. Antropologías e Historias (pp. 255-276). Buenos Aires: Prometeo Libros.

Gordillo, G. (2006c). ¿Formas modernas de caza y recolección? En G. Gordillo (Comp.), En el Gran Chaco. Antropologías e Historias (pp. 276-296). Buenos Aires: Prometeo Libros. 
Gordillo, G. (2010). Lugares de diablos. Tensiones del espacio y la memoria. Buenos Aires: Prometeo.

Gregor, T. y Tuzin, D. (2001). Comparing Gender in Amazonia y Melanesia: A Theoretical Orientation. En T. Gregor y D. Tuzin (Eds.), Gender in Amazonia and Melanesia. An exploration of the comparative Method (pp. 1-16). California: University of California Press.

Guber, R. (2009). El compromiso profético de los antropólogos sociales argentinos 1960-1976. Avá, $16,11-31$.

Hill, J. H y Mannheim, B. (1992). Language and World View. Annual Review of Anthropology 21, 381-406.

Hirsch, S. (2003). Las Mujeres Guaraníes de Salta en la Esfera Doméstica y Pública: una Aproximación Antropológica. Runa, 24, 213-232.

Hirsch, S. (2008). La mujer indígena en la antropología argentina: una breve reseña. En S. Hirsch (Coord.), Mujeres Indígenas en la Argentina. Cuerpo, Trabajo y Poder (pp. 15-25). Buenos Aires: Biblos.

Idoyaga Molina, A. (1976). Matrimonio y Pasión Amorosa entre los Mataco. Scripta Ethonologica, 4, 46-67.

Idoyaga Molina, A. (1976/77). Aproximación hermenéutica a las nociones de concepción, gravidez y alumbramiento entre los pilagá del Chaco central. Scripta Ethnologica, 4 (II), 78-98.

Idoyaga Molina, A. (1986/87). Estudio fenomenológico del mito de origen de las mujeres entre los pilagá (Chaco central). Anales de Arqueología y Etnología, 41-42, 165-174.

Idoyaga Molina, A. (1999). Sexualidad, Reproducción y Aborto. Nociones y prácticas de mujeres indígenas y campesinas de la Argentina. Buenos Aires: CAEA-CONICET.

Karsten, R. (1932). Indian tribes of the Argentine and Bolivian Chaco Ethnological Studies. Helsingfors.

Kidd, S. (1995). Relaciones de género entre los pueblos minimalistas del Chaco paraguayo: una perspectiva teórica y una consideración de los cambios actuales. Suplemento Antropológico, 30, 7-44.

Lagnes, L. y Frank, G. (1981). Lives: in Anthropological Approach to Biography. California: Chandler and Sharp.

Lamas, M. (1995). Cuerpo e identidad. En L. Arango, M. León y M. Viveros (Comps.), Género e identidad. Ensayos sobre lo femenino y lo masculino (pp. 154-176). México: Uniandes.

Lamas, M. (2000). Género, diferencias de sexo y diferencia sexual. En H. Birgin (Coord.), Identidad Femenina y Discurso jurídico (pp. 65-84). Buenos Aires: Biblos.

Leacock, E. (1981). Myths of Male Dominance: Collected Articles on Women Cross-Culturally. Nueva York: Monthly Review Press.

Linde, Ch. (1993). What is a Life Story? En Life Stories. The creation of coherence. Nueva York: Oxford University Press.

Mashnshnek, C. (1986). Acerca de las ideas de menarca, concepción, alumbramiento e infanticidio entre los ayoreo del Chaco Boreal. Scripta Ethnologica, 10, 47-53.

Mendoza, M. (2002). Band Mobility and Leadership among the Western Toba Hunter-Gatherers of Gran Chaco in Argentina. The Edwin Mellen Press. 
Mètraux, A. (1931). La mujer en las sociedades primitivas. Azul Revista de Ciencias y Letras, 2(10), 121-139.

Mètraux, A. (1948). La mujer en la vida social y religiosa de los indios Chiriguanos”. Reseña y trabajos científicos del XXVI Congreso Internacional de Americanistas (Sevilla 1945), I, 416-430.

Mètraux, A. 1980 [1937]. Studies of Toba-Pilagá Ethnography (Gran Chaco). New Haven: Human Relations Area Files.

Miller, E. (1975). Shamans, power symbols, and change in Argentine Toba Culture. American Ethnologist, 2(3), 477-496.

Montani, R. (2008). Metáforas sólidas del género: mujeres y tejido entre los wichí. En S. Hirsch (Coord.), Mujeres Indígenas en la Argentina. Cuerpo, Trabajo y Poder (pp. 153-177).

Buenos Aires: Biblos.

Moore, H. (1988). Feminism and Anthropology. Minneapolis: University of Minnesota Press.

Moore, H. (2007). The subject of Anthropology. Gender, Symbolism and Psychoanalysis. London: Polity.

Nordenskiöld, Erland (2002). La vida de los indios (1912). La Paz: APCOB.

Overing, J. (1986). Men control women? The 'catch 22' in the analysis of gender. International Journal of Moral and Social Studies, 1(2), 135-156.

Palmer, J. (2005). La buena voluntad wichí. Una espiritualidad indígena. Formosa: APCD-CECAZOEPRAZOL-Grupo de Trabajo Ruta 81.

Perazzi, P. (2003). Hermeneútica de la barbarie. Una historia de la antropología en Buenos Aires, 1935-1966. Buenos Aires: Sociedad Argentina de Antropología.

Ramos, A. (1998). The Hyperreal Indian, En: Indigenism, Ethnic politics in Brazil (pp. 267-283). Madison: The University of Wisconsin Press.

Ramos, R. (2012). The politics of Perspectivism. Annual Review of Anthropology, 41, 481-494.

Rubin, G. (1986) [1975]. El tráfico de mujeres: notas sobre la 'economía política' del sexo. Nueva Antropología, 8 (30), 95-145.

Sahlins, M. (1988). Islas de Historia. La muerte del capitán Cook, metáfora, antropología e historia. Barcelona, Gedisa.

Saltalamacchia, H. (1992). La historia de vida. Buenos Aires: Centro Editor de América Latina.

Sciortino, S. (2013). Una etnografía en los Encuentros Nacionales de Mujeres: políticas de identidad desde la afirmación de las “mujeres de los pueblos originarios”. Tesis de Doctorado, Universidad de Buenos Aires, Facultad de Filosofía y Letras.

Sciortino, S. (2015). Procesos de organización política de las mujeres indígenas en el movimiento amplio de mujeres en Argentina. Consideraciones sobre el feminismo desde la perspectiva indígena. Universitas Humanística, 79, 65-87.

Seeger, A., Da Matta, R. y Viveiros de Castro, E. (1979). A construção da pessoa nas sociedades indígenas Brasileiras. Boletim do Museu Nacional, 32, 2-49.

Segato, R. (2003). Las estructuras elementales de la violencia. Ensayos sobre género entre la antropología, el psicoanálisis y los derechos humanos. Universidad Nacional de Quilmes: Prometeo. 
Tiscornia, S. y Golier, C. (1984). Hermeneútica y fenomenología: exposición crítica del método fenomenológico de Marcelo Bórmida. Etnía, 31, 20-38.

Tola, F. (1999). Fluidos corporales y roles paternos en el proceso de gestación entre los qom orientales (qom) de la provincia de Formosa. Papeles de Trabajo, 8, 197-221.

Tola, F. (2001). Ser madre en un cuerpo nuevo: procesos de cambio en las representaciones qom de la gestación. Relaciones, XXVI, 57-72.

Tola, F. (2006). Estrategias matrimoniales en el proceso de repliegue y apertura de las parentelas toba (qom). Revista de Antropología, 49(2), 668-687.

Tola, F. (2008). Constitución del cuerpo femenino entre los qom (qom) del este formoseño. En S. Hirsch (Coord.), Mujeres Indígenas en la Argentina. Cuerpo, Trabajo y Poder (pp. 59-78). Buenos Aires: Biblos.

Tola, F. (2012). Yo no estoy solo en mi cuerpo. Cuerpos-personas múltiples entre los qom del Chaco Argentino. Buenos Aires: Biblos.

Tola, F. (2016). El 'giro ontológico' y la relación Naturaleza/Cultura. Reflexiones desde el Gran Chaco. Apuntes de Investigación del Cecyp, 27, 129-139.

Tola, F., Medrano, C. y Cardin, L. (Eds.) (2013). Gran Chaco. Ontología, poder, afectividad. Buenos Aires: Ethnographica.

Torres Fernández, P. (2006). Proyectos, Discursos y Políticas Misionales en el Chaco CentroOccidental durante la primera mitad del siglo XX. Tesis de licenciatura, Facultad de Filosofía y Letras, Universidad de Buenos Aires.

Trinchero, H. y Maranta, A. (1987). Las crisis reveladoras: historia y estrategias de la identidad entre los mataco-wichí del Chaco centro-occidental. Cuadernos de Historia Regional, 4(10), 74-92. Viveiros de Castro, E. (1993). Alguns aspectos da afinidade no Dravidianato Amazônico. En E. V. de Castro y M. C. da Cunha (Eds.), Etnología e história indígena (pp.149-210). São Paulo: FAPESP.

Viveiros de Castro, E. (2004). Perspectivismo y multinaturalismo en la América Indígena. En A. Surrallès, P. García Hierro (Org.), Tierra adentro: territorio indígena y percepción del Entorno (pp. 37-80). Buenos Aires: IWGIA.

Viveiros de Castro, E. (2010). Metafísicas Caníbales: Líneas de Antropología Postestructural. Buenos Aires: Conocimiento.

Wright, P. (1983). Presencia protestante entre aborígenes del Chaco Argentino. Scripta Ethnologica, 2, 73-84.

Wright, P. (1988). Tradición y aculturación en una organización socio-religiosa toba contemporánea. Cristianismo y Sociedad, 95, 71-87.

Wright, P. (2003). Colonización del espacio, la palabra y el cuerpo en el Chaco Argentino. Horizontes Antropológicos, 9(19), 137-152.

Wright, P. (2008). Ser-en-el-sueño. Crónicas de historia y vida toba. Buenos Aires: Biblos.

Wright, S. (2004). La politización de la 'cultura. En M. Boivin, A. Rosato y V. Arribas (Comps.), Constructores de Otredad. Una introducción a la antropología social y cultural (pp. 128-141). Buenos Aires: Antropofagia. 


\section{BIBLIOGRAPHY}

Bibliografía

\section{NOTES}

1. Entre las influencias de Bórmida, Gordillo (2006b, p. 57) menciona: la obra temprana de Edmund Husserl, la influencia de la filosofía idealista y antipositivista de Benedetto Croce (dominante en la Italia fascista en la que Bórmida hizo sus primeros estudios), Lucien Lévy-Bruhl, Adolf Jensen, Bronislaw Malinowsky, Maurice Leenhardt, la temprana influencia de la escuela histórico-cultural a través de José Imbelloni y Oswald Menghin, prehistoriador que mantenía lazos con el nazismo en Austria y por ello emigró a la Argentina tras la Segunda Guerra Mundial.

2. Esta corriente fue criticada también por otros autores a partir del regreso de la democracia al país y de renovados intereses teóricos y políticos al interior de la disciplina (Cordeu y De los Ríos 1982; Tiscornia y Golier 1984; Perazzi 2003).

3. La autora hace explícito su intento por integrar el impacto de los cambios socio-históricos en el estudio de dichos tópicos. Sin embargo, muestra una fiel continuidad con la escuela bormidiana en sus diversas conceptualizaciones: "representaciones culturales de orden mítico" (1999, p. 10), "sistema de representaciones tradicional" (p. 16), "horizonte o tradición cultural que no se altera esencialmente" (pp. 15-16), "estructura de pensamiento de la cultura nativa" (p. 22) y "conciencia aborigen".

4. En sus últimos trabajos se distancia de esta interpretación y elabora una distinta: “...el carácter inestable, metamórfico y andrógino de los humores corporales que condensan y trasmiten características tanto masculinas como femeninas" (Tola 2008a, p. 67; 2008b).

5. Tal vez en estas preguntas que se formularon algunos/as antropólogos/as del Chaco y de la etnología sudamericana hayan tenido influencia los primeros Estudios de la Mujer y la antropología de género transcultural de las décadas del 70 y 80 (Collier 1974) pues fueron los primeros en interrogarse por las formas de participación política y participación en la toma de decisiones en las que se veían involucradas las mujeres en las "sociedades simples".

6. Según Mendoza (2002, p. 108), entre los qom del oeste antiguamente existían tres tipos de liderazgo masculino: uno guerrero, uno religioso y otro político, representado en la figura de los jaliaganec, pero generalmente un mismo hombre concentraba los tres liderazgos. "Cada actividad masculina (económica, religiosa y política) tenía su contraparte en el dominio femenino, con excepción del rol de guerrero. Los hombres contribuían con presas, pescado y miel, y las mujeres proveían vegetales silvestres, agua y leña para mantener los fuegos vivos. Algunos hombres ocasionalmente cultivaban los huertos y otros criaban caballos (...) Tanto los hombres como las mujeres fueron iniciados como shamanes, a pesar de que solo las mujeres fueron vistas como brujas. La mujer de un líder de banda (jaliaganá) era influyente sobre las otras mujeres y contribuía al mantenimiento de las relaciones sociales igualitarias entre las bandas" (Mendoza 2002, p. 108).

7. Su postura se retrotrae a los argumentos de Leacock (1981) para quien las transformaciones en las relaciones de género y en la posición de la mujer en los grupos cazadores-recolectores habrían surgido de la articulación de tres procesos: colonialismo, misionalización e imperialismo. 8. Para comprender la posición social de las mujeres en el pasado, analicé fuentes primarias (los documentos de los misioneros anglicanos escritos a lo largo de 5 décadas): aquí hice una 
relectura de aquellas actividades que las fuentes anglicanas describían desde las categorías de la antropología feminista especializada en estudios de género en sociedades cazadoras-recolectoras, dialogando con algunas ideas precedentes propuestas en estudios etnográficos del chaco de corte más sociológico (Braunstein 1974, 1983). En esta etapa de la investigación me resultó muy útil la categoría "sistemas de sexo-género" (Rubin 1975) ya que articula el funcionamiento de los sistemas de parentesco con los sistemas de género para entender la posición social de las mujeres en sociedades cazadoras-recolectoras con sistema de parentesco matrilocales o brideservice (Collier y Rosaldo 1981) y en relación a las condiciones de producción o a la economía política de este tipo de sociedades. Siguiendo este camino, concluí que a los inicios del proceso de conversión socio-religiosa anglicana las mujeres tomaban decisiones que tenían que ver con los arreglos matrimoniales (el sistema de alianzas), tenían una participación muy activa en la economía política de sus grupos al defender los intereses de sus familias matrilocales y, llegado el caso, podían enfrentarse mediante luchas de mujeres por la competencia en torno a los hombres, es decir para retener a los hombres que habían ingresado en sus familias en calidad de maridos o yernos. Esta activa participación de las mujeres en la economía política y en el parentesco, no obstante, estaba contenida dentro de una ideología de género patriarcal en donde los hombres en su rol de proveedores tienen un alto valor social, independiente de su correlato empírico, pues las fuentes anglicanas y las primeras monografías etnográficas narran que las mujeres también aportaban grandes cantidades de alimentos a las unidades domésticas. Cabe destacar que los roles de liderazgo político, religioso y guerrero también estaban destinados a los hombres, no a las mujeres. El simbolismo de género que se manifiesta en muchos mitos tobas posiciona a las mujeres no en un lugar de debilidad, sino en uno de abyección, potente monstruosidad y deshumanización, transgresión y polución. Con respecto a los impactos del proceso de misionalización en la posición social de las mujeres concluí que este produjo una represión sobre prácticas y esferas de acción femeninas mediante las cuales ellas participaban en la economía política de sus grupos (como las peleas de mujeres), una gradual reclusión en espacios domésticos que cada vez más se fueron fijando al espacio de la misión, en el marco de un proceso de sedentarización mayor que estaban viviendo los grupos indígenas del chaco desde que comenzaron a trabajar en las agroindustrias de la región; por último, mediante una política de género que estaba implícita en la política general de las misiones anglicanas concluí que las mujeres fueron un sujeto secundario en el proceso de conversión, que fueron excluidas de la nueva estructura de liderazgo religioso que crearon los misioneros y que fueron objeto de una política que buscaba maternizarlas, domesticarlas y volverlas laboriosas artesanas. Las fuentes anglicanas dan cuenta que, durante las primeras dos décadas de funcionamiento de la misión, resistieron estas imposiciones pero luego fueron cooptadas por el nuevo orden misional, y especialmente, por la ideología de género cristiana que sacraliza, santifica y demoniza, mediante asociaciones simbólicas, a las mujeres y a una serie de prácticas culturales.

9. Tales son las categorías con las que se refieren los y las tobas a estos tiempos distintos que vivieron las diferentes generaciones.

10. El concepto "construcción cultural del género" lo tomé de Marta Lamas $(1995,2000)$ y comprende según esta autora tres niveles de análisis: 1) La diferencia anatómica entre los sexos como una diferencia biológica, observable y leída culturalmente que, si bien la mayoría de las culturas la simbolizan binariamente, en realidad se muestra más como un continuo con una variedad de combinaciones de caracteres, estando sus extremos representados por lo masculino y lo femenino; 2) Las ideas, las prácticas, las representaciones y las prescripciones en torno a lo que se considera en cada sociedad como propiamente masculino y femenino, tomando como base la diferencia anatómica entre los sexos; 3) La diferencia sexual que implica un proceso inconsciente de asunción de una orientación sexual, dentro de cuatro posibilidades (heterosexualidad, homosexualidad femenina, masculina y bisexualidad). Este sería un proceso individual, psíquico, 
inconsciente e inestable, donde lo social no es un factor determinante sino lo psíquico-corporal. Implica la articulación entre cuerpo, sociedad y psiquis (Lamas 2000, p. 72).

11. La idea de que cada cultura elaboraría su propia gramática sobre el género codificable en una estructura simbólica particular, histórica y contingente parece ser el acuerdo alcanzado en buena parte de la teoría feminista actual, representada especialmente en la postura de Judith Butler (2002), quien afirma, a diferencia de las posturas psicoanalíticas más tradicionales, que el orden simbólico es un ámbito históricamente variable desde el cual se realiza la materialidad y la diferenciación de los cuerpos. Desde esta postura, el orden simbólico en tanto norma, ley y/o poder regulador no sería una estructura permanente que se repite universalmente en todos los procesos de sexuación y constitución de los sujetos.

12. El habitus como concepto (Bourdieu 1986, 1991, 2006) expresa una síntesis temporal prácticocorporal-narrativa de los procesos de subjetivación por los que atravesaron los sujetos. De este modo, el habitus viene a representar una substanciación o una condensación temporaria de la subjetividad: una encarnación pasible de reconstruirse en el análisis considerando los efectos que decantaron de aquellos procesos de subjetivación por los que una persona atravesó y atraviesa y que, no obstante, considero que no están clausurados, como sí parecen estarlo desde la teoría de Bourdieu, para quien el habitus más que una condensación representa una cristalización de las determinaciones ideológicas a las que están sometidos los individuos en tanto agentes sociales.

13. El término procesos de subjetivación refiere a los procesos mediante los cuales se estructura (temporalmente) la subjetividad de una persona, reconociendo que el género es una variable fundamental en dichos procesos (Braidotti 2000). Por otra parte, la categoría de subjetividad implica la articulación de dinámicas más complejas que las vinculadas a la conformación de una identidad de género, pues posee una impronta fenomenológica ya que remite a procesos y prácticas que abarcan pero desbordan la actividad de la conciencia y la autorreflexión, remitiéndose a modos de estar en el mundo y ser un cuerpo situado (Castellanos 2008).

14. Cabe remarcar que los relatos reconstruidos en base a memorizar experiencias pasadas, estas no son "el pasado" ni lo "real" sino un pasado evocado y narrado desde un presente particular (Candau 2001). Así, estos relatos toman significado en la situación etnográfica y en el cruce intersubjetivo que se implica en la búsqueda de comprensión y negociación de los significados culturales.

15. "En numerosas sociedades hay representaciones que describen un mundo lejano o abolido donde la cosas ocurren a la inversa de cómo se dan realmente en su seno. Así, en sociedades con fuerte dominación masculina se hallan mitos que describen una época hace mucho tiempo desaparecida en que las mujeres dominaban a los hombres. Por supuesto, lejos de hacer una apología del poder de las mujeres o de ser huella objetiva de una época pasada, esos mitos son un instrumento suplementario de la dominación masculina, puesto que confronta los órdenes y calamidades que provoca el ejercicio del poder por parte de las mujeres" (1990, p.84).

16. “...los maoríes son astutos mitólogos, capaces de seleccionar del rico conjunto de tradiciones las más adecuadas para satisfacer sus intereses del momento, como ellos los entienden" (1988, p. 65).

\section{ABSTRACTS}

The present article makes a critical approach of what I call a cosmologicistic approach to the gender of the Chaco indigenous women which has been constructed through some constants ethnographic 
dimensions (the initiation ritual, myths, the gender-based distribution of work) that known authors of the region have used to analyze the gender symbolic structure and the place of women in Tobas (Qom) and Wichí groups. I then focus on pointing out two problematic aspects that hover around this approach: 1) A static gender condition; 2) Omissions about gender inequalities. Finally, I show an alternative approach and analysis based on my ethnography with Toba women.

El artículo realiza una aproximación crítica a lo que denomino mirada cosmologicista sobre el género de las mujeres indígenas del Chaco, la cual ha sido construida a partir de dimensiones etnográficas constantes (el ritual de iniciación, los mitos, la división sexual del trabajo) que autores reconocidos de la región utilizaron para analizar la estructura simbólica de género y el lugar de las mujeres en los grupos tobas (qom) y wichís. Luego me concentro en señalar dos aspectos problemáticos que gravitan alrededor de esta mirada: 1) una condición de género estática; 2) omisiones sobre la desigualdad de género. Finalmente, muestro un abordaje y análisis alternativo basándome en mi etnografía con mujeres tobas (qom).

\section{INDEX}

Palabras claves: Género, Cosmología, Chaco, Mujeres indígenas, Argentina

\section{AUTHOR}

\section{MARIANA D. GÓMEZ.}

CONICET- Instituto de Ciencias Antropológicas-Sección Etnología y Etnografía, Facultad de Filosofía y Letras. UBA. Argentina.

Correo electrónico: marianadanielagomez35@gmail.com y gomin19@yahoo.com 